Revista do Programa de Pós-Graduação em Artes da Cena,

Universidade Estadual de Campinas

Performing Arts Graduate Program Journal, University of

Campinas

\title{
Primeiras incursões na arte do encontro
}

\author{
First incursions into the art of meeting
}

Katharina Souza Câmaral $^{1}$

Submetido em: 08/11/2018

Aceito em: 27/07/2019

Publicado em: 29/08/2019

\section{Resumo}

Escrito na forma de ensaio sobre a "ficha-corpo" e sobre o trabalho de conclusão do bacharelado em Dança da autora, este artigo propõe-se a explorar conceitos de lugar, corpografia e performances nas ruas.

Palavras-chave: Dança. Lugares não-espetaculares. Corpografia.

\section{Abstract}

Written in the format of an essay on the author's "body-form" and on her final piece for the Dance undergraduate diploma, this paper intends to explore concepts such as place, "bodygraph" and urban performances.

Keywords: Dance. Non-spectacular places. Bodygraph.

A vida, amigo, é a arte do encontro, embora haja tanto desencontro pela vida.

(Vinícius de Moraes)

Ao nos candidatarmos ao curso de dança na Universidade Estadual de Campinas (Unicamp), enviamos, para conhecimento da banca de avaliação da prova específica, um breve currículo, em que descrevemos uma espécie de histórico corporal. Indicamos que modalidades de dança praticamos, por quanto tempo e com quais professores. Alguns podem ter incluído atividades profissionais. No meu caso, procurei citar todas as escolas em que havia feito aulas

\footnotetext{
${ }^{1}$ Estudante do Departamento de Artes Corporais do Instituto de Artes da Universidade Estadual de Campinas (UNICAMP). ORCID: https://orcid.org/0000-0002-1017-0746. Contato: katharinasc@gmail.com
} 
Revista do Programa de Pós-Graduação em Artes da Cena, Universidade Estadual de Campinas

Performing Arts Graduate Program Journal, University of Campinas

e todas as modalidades possíveis, ainda que tenham sido experiências breves. Minha ficha teria que ser preenchida ao máximo.

Naquela época, eu tinha uma visão de corpo e dança muito diferente da que tenho hoje. Hoje, talvez, eu tivesse incluído na minha ficha meu hábito incorrigível de me perder e minha aversão a GPS, além de uma extensa pesquisa que fiz nas ruas de Campinas, perguntando às pessoas que passavam se poderiam me ceder cinco minutos de seu tempo. Se, antes, eu imaginava que minha experiência corporal se resumia às práticas convencionais realizadas em espaços pensados para elas, como as academias de dança, eu ignorava o quanto minha "fichacorpo" já estava lotada de palavras, rabiscada frente e verso e cheia de rasuras.

Tudo que eu queria era aprender a dançar. Contudo, já no curso de Dança, eu me vi cada vez mais longe de aprender aquilo que eu chamava de dança. Eu viria a descobrir que este aprendizado seria como se perder em lugares desconhecidos. Fui me especializando em me perder - e isso aconteceu literalmente, já que eu costumo me propor caminhadas nas cidades que frequento. Os pontos de referência surgiram aos poucos, mas o desconhecido não acabava nunca. As ruas que lembravam algo que já tinha visto - embora fossem, na verdade, irreconhecíveis - se desdobravam em travessas, praças, becos sem saídas, linhas de trem, quarteirões sem esquina e na aposta de que, mais à frente, poderia estar o fim do labirinto. Nesses anos de formação na Unicamp, fui instigada a evitar caminhos conhecidos e preestabelecidos e pude percorrer novos - únicos em suas percepções, pontos de partida, jornadas e pontos de chegada. Cada vez mais, eu me vi criando dança, uma dança que nunca estará pronta e, portanto, jamais poderá ser completamente aprendida.

Como pode acontecer quando nos perdermos, há momentos de certa aflição, mas também aqueles muito gratificantes, como quando se descobre um café bonitinho com uma vitrine apetitosa num lugar inesperado. Assim, quando cheguei ao quarto ano do curso de dança, ano de realizar nosso trabalho de conclusão de curso (TCC), devo ter sido tomada pelo medo de sair de casa, não conseguir voltar e só me deparar com becos sem saída. O medo cedeu lugar à confiança no inexplorado quando encontrei um cantinho aconchegante - fui acolhida no grupo de TCC orientado pela professora Holly Cavrell. 
Revista do Programa de Pós-Graduação em Artes da Cena,

Universidade Estadual de Campinas

Performing Arts Graduate Program Journal, University of

Campinas

\section{Cartografia teórica}

A proposta da professora era que nos desafiássemos, dançando em lugares onde a dança não é esperada. Holly Cavrell já havia desenvolvido com sua companhia, a Dominío Público, diversas obras para espaços não convencionais à dança. Não se trata de trabalhos site specific, pois, embora as obras requeiram interação profunda com o espaço, uma mesma peça pode se desenvolver em lugares diversos, não sendo, portanto, construída em um local específico nem destinada a apresentações somente nesse lugar. Tendo sido apresentada mais de cem vezes em lugares diferentes, um dos desafios dos bailarinos de "Posso dançar pra você?", da Domínio Público, era tornar-se parte da estrutura e dos fluxos que existiam no lugar, criando, sobretudo, uma empatia quase instantânea com as pessoas para quem aqueles lugares eram convencionais.

A ida da dança para lugares outros, que não os palcos e teatros, data dos anos $1960 \mathrm{e}$ 1970, com o movimento Judson Church nos Estados Unidos (CAVRELL, 2017). A dança e outras formas de arte colocaram-se, então, uma série de questionamentos, particularmente sobre seus códigos e materiais, assim como sobre quem é e o que faz o artista. Ao trazer para a performance gestos cotidianos e movimentos comuns, a dança também acabou buscando lugares comuns e cotidianos. O uso cênico de diversos elementos da vida rotineira propiciou uma reflexão sobre o que é dança, onde ela acontece e quem a pratica. A explosão dos limites daquilo que é próprio à dança fez explodir também a noção de corpo próprio à dança - isto é, passou-se a questionar quais devem ser o corpo e a função do bailarino. No que difere o bailarino, o corpo que dança, do espectador, corpo que não-dança? Quando a dança acontece em lugares que não lhe são convencionais, especialmente nos espaços urbanos abertos à circulação, tudo está em cena, inclusive os transeuntes. Por isso, essas pessoas também se tornam performers da cena, atuantes sobre o sentido que ali se produz.

Mais adiante, vamos voltar à questão da participação do público na cena. Por ora, gostaria de destacar que, ao optar² por dançar e criar dança para espaços não-convencionais, trabalha-se com um espaço que, em comparação com as caixas pretas convencionais, é

\footnotetext{
${ }^{2}$ Nem sempre a busca por espaços não convencionais é uma opção: não raro, artistas e grupos têm dificuldades de financiar locais de prática e de apresentação mais tradicionais.
} 
Revista do Programa de Pós-Graduação em Artes da Cena, Universidade Estadual de Campinas

Performing Arts Graduate Program Journal, University of Campinas

altamente identitário. Digo identitário no sentido de que não admite tantas máscaras. Muitas vezes, esquecemos ou ignoramos que, como coloca Lepecki (2010), o chão que normalmente consideramos próprio para a dança é um solo violentado, transformado e criado artificialmente para que possamos dançar. Assim, enquanto os espaços tradicionais são relativamente mais maleáveis - no sentido de que admitem movimentos, cenografias, iluminações, sonoplastias, ou seja, máscaras diversas -, os espaços não-convencionais são pouco flexíveis. Se naquele caso, o artista traz para a composição elementos alheios ao espaço, neste é o artista quem se reconfigura a partir de elementos característicos que recebe do espaço.

Precisamos aqui aprofundar o entendimento que se tem por lugares não-convencionais como lugares alternativos aos espaços cênicos tradicionais, a exemplo de palcos e teatros. Para nosso trabalho de conclusão de curso, buscávamos não apenas quaisquer lugares diferentes dos espaços tradicionais, mas lugares que, ainda seguindo o pensamento de Lepecki (2010), não estivessem de certa forma "neutralizados" pela ilusão de subjetividade e autonomia. Tal ilusão está implícita na ideia movimento livre, independente e sem obstáculos que acontece nas salas e chãos de dança tradicionais. Era preciso buscar lugares que fossem de fato lugares. Nesse sentido, Carreira (2007) e Jacques (2008) diferenciam lugares dos não-lugares e dos lugares espetaculares, respectivamente. Ambos os autores definem "lugar" como local de identidade, de relação entre pessoas, de memória coletiva e individual. Esses locais caracterizam-se pela experiência das trocas complexas feitas entre quem os ocupa e entre essas pessoas e as estruturas físicas e simbólicas que conformam os espaços.

Ao investigar o teatro de rua, Carreira (2007, p. 4) lembra que "o espaço social da rua nunca é neutro". Recorrendo a Marc Augé (1998 apud CARREIRA, 2007, p. 13), o autor define não-lugares como "espaços que não são em si lugares antropológicos, espaços que não se definem pela construção da 'memória'. Esta classe de espaço trata de simular representações como é o caso dos shoppings centers - de uma cidade na qual o conflito não existe". Se entendemos o conflito como a própria interação entre diferenças, diversidades e desigualdades, logo concluímos que não há, no conflito, espaço irrestrito e totalmente autônomo para a convivência de subjetividades múltiplas e independentes entre si. Desfeita a ilusão da modernidade a respeito da subjetividade autônoma (LEPECKI, 2010), observamos que a 
Revista do Programa de Pós-Graduação em Artes da Cena, Universidade Estadual de Campinas

Performing Arts Graduate Program Journal, University of Campinas

subjetividade, além de ser limitada por aquilo que está a seu redor, é também conformada por esse meio, não sendo, portanto, fruto ou expressão máxima de um único indivíduo. Construímo-nos a partir da exposição às diferenças, aos conflitos. Um lugar sem conflitos é um lugar que foi pasteurizado, dando a ilusão de homogeneidade e de completude, como se minha subjetividade já houvesse concluído qualquer processo formativo e estivesse agora no mundo para viver-se irrestritamente.

Também Jacques (2008) usa um termo negativo para caracterizar tudo que não é lugar: são locais de "não-experiência". A autora usa o conceito de corpografia para identificar as experiências encarnadas no corpo. E, se observa "corpografias espetaculares, superficiais", acredita igualmente nas corpografias de "resistência à espetacularização, ou seja, o oposto do corpo mercadoria, imagem ou simulacro, produto da própria espetacularização contemporânea" (JACQUES, 2008, p. 5). Ela enxerga nas corpografias urbanas, resultado do corpo em interação com a cidade, uma possibilidade de escapar dos processos de espetacularização, que assim como pasteurizam os lugares, neutralizam a potência da participação cidadã e da "experiência corporal das cidades enquanto prática cotidiana, estética ou artística no mundo contemporâneo" (JACQUES, 2008, p. 1). Por corpografia, a autora entende o registro de uma experiência vivida que fica inscrita no corpo e o configura.

Assim, vi nesse conceito uma semelhança com a "ficha-corpo" que mencionei no começo do texto. Percebi ainda que minha ficha tinha conteúdo além do que eu imaginava e incluía até mesmo minhas aventuras sem rumo pelas ruas das cidades, pois Jacques (2008) descreve a "errância" pela cidade como um dos mais potentes estímulos para as vivências urbanas, geradoras de uma corpografia urbana complexa e profunda.

Quando nos perdemos, a relação do nosso corpo com o tempo e o espaço que nos cercam se transforma. Nosso passo se torna lento e nosso olhar, mais atento (JACQUES, 2008). Na errância, isto é, no ato de se perder que propicia inscrições cuidadosas e intensas da cidade no corpo, encontrei algo que legitimasse muitas das minhas vivências na cidade. Não que qualquer pessoa precise desse conceito para legitimar suas vivências. Mas eu comecei a reparar que trazia comigo corpografias urbanas e passei a enxergar como memória significativa e fonte de conhecimento algumas das experiências que geraram essas inscrições. No que diz respeito 
Revista do Programa de Pós-Graduação em Artes da Cena, Universidade Estadual de Campinas

Performing Arts Graduate Program Journal, University of Campinas

à dança, por exemplo, percebi que meu corpo dançante não estava confinado às salas de aula de pisos aplainados. Percebi que minha história não estava toda contida nesses lugares, de modo que a percepção de outras situações que eu já tinha vivido se transformou.

\section{Minhas corpografias urbanas}

Há inúmeras memórias inscritas em meu corpo que não vou saber descrever. Com certeza, todas contribuem para que eu me mova como hoje me movo. Duas, porém, foram bastante intensas e significativas para uma corpografia urbana, por me colocar num contato mais direto, profundo e transformador com a cidade. Descrevo-as nos parágrafos seguintes.

Numa pesquisa acadêmica que realizei entre os anos de 2013 e 2014, estive em locais movimentados (bairros centrais e terminais de ônibus) de Campinas, pedindo aos passantes que respondessem a um questionário. Eu, que nunca havia dado muita atenção a essas pesquisas, penei para ganhar o olhar, o ouvido e corpo de, pelo menos, uma centena de pessoas. A correria era tanta que a empatia entre mim e a pessoa entrevistada precisava ser gerada quase que instantaneamente. O questionário, de duração ideal de 20 minutos, tornou-se um trava-línguas de 5 minutos que poderia, contudo, se estender por meia hora. A linguagem era totalmente adaptável, sem, porém, permitir vieses de compreensão por parte dos entrevistados. O figurino tinha um quê de neutralidade, profissionalismo e cordialidade. Os dois apoios dos pés por horas carregavam meu corpo, num ato de resistência, que também caminhava em busca de melhores pontos de abordagem dos passantes e, quando requisitado, acompanhava em uníssono os entrevistados.

Sem muita consciência disto, logo me tornei mais íntima das ruas, de seus fluxos e estruturas. Para essa aproximação, contribuiria a segunda experiência que considero fundamental. Trata-se da residência de que participei em 2015, na Bienal Sesc de Dança em Campinas, bodies in urban spaces (corpos em espaços urbanos). Dirigido no Brasil por Ian Dolan, membro da Cie. Willi Dorner, o trabalho da companhia austríaca já havia sido levado a outras partes do mundo e suas apresentações costumavam recrutar performers que viviam nos países visitados. A peça é descrita desta maneira: 
Revista do Programa de Pós-Graduação em Artes da Cena, Universidade Estadual de Campinas

Performing Arts Graduate Program Journal, University of Campinas

\begin{abstract}
A intenção de "corpos em espaços urbanos" é evidenciar a estrutura urbana funcional e revelar possibilidades restritas de movimento e comportamento, assim como regras e limitações. Ao posicionar corpos nos locais selecionados, as intervenções provocam um processo de reflexão e produzem irritação. Transeuntes, residentes e público são motivados e incentivados a refletir sobre seu entorno urbano e seus próprios hábitos de movimento e comportamento. "Corpos em espaços urbanos" convida residentes a andar por seu próprio bairro, estabelecendo uma relação mais forte com a vizinhança, com a região e com a cidade. As intervenções são temporárias e não deixam vestígios, mas imprimem cenas na memória visual (CIE WILLI DORNER, 2007, Tradução da autora).
\end{abstract}

Por que a intervenção provoca irritação? Poderíamos encontrar motivos na situação de confronto criada pela performance ao destacar-se do cenário urbano cotidiano, obstruindo-o. As cores chamativas das roupas dos participantes e as esculturas humanas certamente contrastavam com o visual do centro da cidade. Também pareciam opostas a seus usos, determinados pelos fluxos e estruturas habituais. Em grupos, nós corríamos pelas ruas cheias de gente, e montávamos rapidamente uma forma (como mostra a Figura 1), que mantínhamos por alguns minutos. Certamente muitos passantes se surpreendiam com o que viam. Mas de onde exatamente vem a irritação?

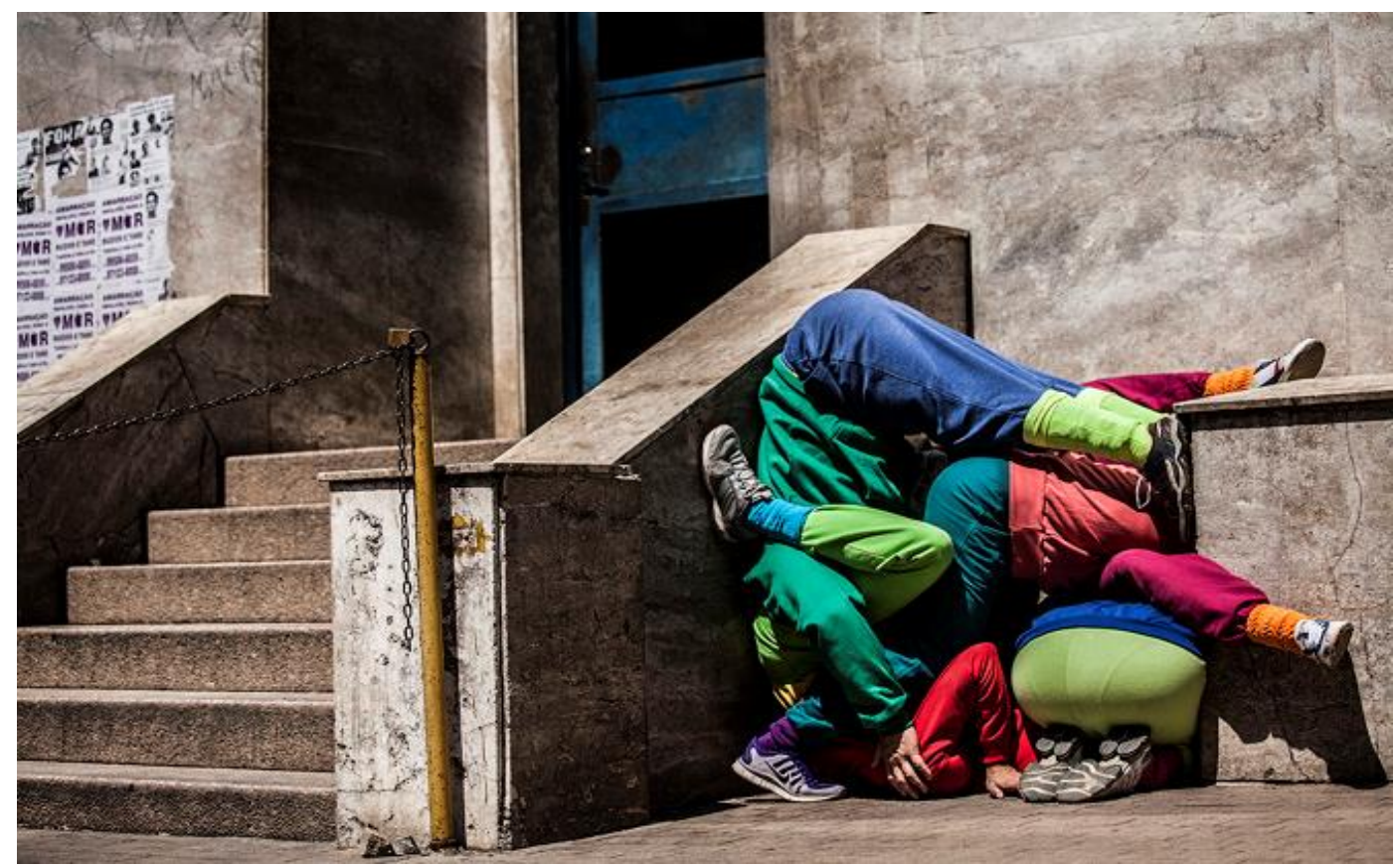

Figura 1 - Corpos em Espaços Urbanos. Campinas, 2015. Foto: Tamara Tanaka. 
Revista do Programa de Pós-Graduação em Artes da Cena, Universidade Estadual de Campinas

Performing Arts Graduate Program Journal, University of Campinas

Dois anos depois dessas experiências, à época do processo de criação do TCC, não foi difícil para mim vislumbrar a potência do corpo desobediente (RIBEIRO, 2017), do corpo subversivo que é onde não deveria ser. Vi-me propondo outros espaços para meus aquecimentos de dança. Fiz exercícios de yoga e de improvisos com música em lugares inusitados pelo campus da universidade. Já com o grupo de TCC, propusemo-nos a pesquisar os lugares do nosso dia a dia. Nosso primeiro exercício foi o de vivenciar mais atentamente esse cotidiano, revisitando espaços agora como artistas que não procuravam avidamente, mas simplesmente aguçavam a percepção. Cada vez mais, nossos ensaios e experimentos buscaram o lado de fora das salas de aula e fugiram dos lugares comuns à dança.

\section{Encontros}

Cabe aqui comentar um pouco sobre nós. Éramos então um grupo de estudantes sem muita intimidade uma com a outra, reunidas pelo motivo funcional de terminar o curso. Talvez, por isso, viríamos a enxergar nos encontros - casuais, propositais, cotidianos, inesperados uma nova motivação. Começávamos também a nos encontrar, perdendo-nos juntas num caminho de fim desconhecido. Quisemos então captar a intimidade de duas pessoas se abraçando em meio à correria cotidiana, a sutileza de um sorriso trocado entre dois estranhos que realizam algo mais que uma transação de compra e venda, a misteriosa empatia que surge numa conversa jogada fora. Desejosas de investigar tudo que acontece a despeito da lógica utilitária que penetra nossas vidas e modela muitas de nossas ações, tornando-as meramente funcionais, permitimo-nos enxergar além do fim do curso, do fim do dia, e do fim das horas de ensaio obrigatórias.

Dessa forma, inquietamo-nos com o que nos pareceu mais comum: os desencontros. Perguntamo-nos, surpresas, apesar da indiferença na fala e no olhar, da individualidade de nossas ações, das metas de eficiência e produtividade, como são produzidos os encontros? Os encontros são avessos à indiferença, acontecem na escuta do que está ao nosso redor e, muitas vezes, atrapalham nossos cronogramas de trabalho. Os encontros e desencontros fazem-se 
Revista do Programa de Pós-Graduação em Artes da Cena, Universidade Estadual de Campinas

Performing Arts Graduate Program Journal, University of Campinas

concretos nas ruas e noutros espaços urbanos, penetrando-nos de forma subjetiva, modificando nosso modo de ser e estar no mundo. Dito de outra forma, os ritmos urbanos e outras exigências (imaginadas ou não) dos modos de viver contemporâneos nos colocam em posições de encontros e desencontros conosco mesmos, com os espaços e com outras pessoas. Nessas circunstâncias, criamos uma corpografia composta por emoções, sensações, pensamentos, gestos, movimentos e ritmos de encontros e desencontros. Vivenciando artisticamente alguns ambientes urbanos que faziam parte do nosso cotidiano, pretendíamos descobrir e continuar compondo a corpografia dos nossos corpos (des)encontrados, atentando-nos para os traçados já existentes e estando disponíveis para novas inscrições corporais.

\section{Refazendo caminhos}

Em nossa jornada criativa, exploramos pelo menos dois percursos. Um deles seguiu a pista de vivenciar espaços públicos, já conhecidos nossos, com nosso olhar artístico, despretensioso, porém atento. Algo daí, automaticamente inscrito em nossos corpos, poderia se tornar material de composição. Outro percurso consistiu em montar pequenas peças nas salas de aula de dança e levá-las para outros espaços. Se nos propusemos seguir o rastro do tema do volume anterior deste periódico - intitulado "Babel: tradições, traduções e traições (CONCEIÇÃO/CONCEPTION, 2018) - poderíamos dizer que aí passamos por três momentos: i) questionamos a tradição das apresentações de dança em espaços cênicos; ii) acreditamos, ingenuamente, por algum momento, numa tradução literal do que criávamos em sala de aula ou do que vivíamos nos espaços comuns para outros lugares; iii) fomos, felizmente, traídas pelos percursos que realizamos, que colocaram em xeque nossas ideias sobre dançar em espaços públicos.

Ao refazer caminhos, esperávamos não só nos libertar de certa ilusão de autonomia, como também éramos movidas por uma crença na potência dos encontros de todo dia e na dança que nos é comum a todos. Queríamos nos aproximar do que é comum a mais de uma pessoa, investigando a empatia que surge das situações mais ásperas. Buscamos lugares nãoespetaculares, justamente porque queríamos vivenciar artisticamente o conflito intrínseco às 
Revista do Programa de Pós-Graduação em Artes da Cena, Universidade Estadual de Campinas

Performing Arts Graduate Program Journal, University of Campinas

construções humanas, naturalmente não-neutras. Sabíamos que os desencontros, toda essa aridez humana, são uma face dos conflitos. Nos lugares espetaculares, se não há conflitos, também não há encontros. Era preciso apostar nos aspectos das situações de conflito que não necessariamente os do embate e da indiferença diante daquilo que é diverso de nós. Estávamos interessadas mais especificamente na face do conflito que acomoda o encontro, a empatia, a percepção compassiva de si e da outra pessoa com quem nos relacionamos e que é diferente de nós.

É preciso lembrar que os lugares não-espetaculares abrigam o conflito não apenas por reunirem uma diversidade de pessoas e comportamentos. Existe uma segunda camada de conflito - ou melhor dizendo, contradição - que reside no fato de que os lugares e as pessoas com quem compartilhamos nossas existências não são os lugares e pessoas que povoam nossa imaginação espetacularizada. Nossa imaginação e nossas ideias de como as coisas devem ser são também de certa maneira delineadas pela cultura espetacularizada que padroniza nossas relações, nossos anseios e nossos objetivos de vida. Dito de outra forma, aqueles lugares e pessoas não-espetaculares não existem na nossa ilusão de autonomia - e voltamos a Lepecki (2010). Porém, o espetáculo, isto é, a possibilidade de sucesso na nossa sociedade (total autonomia), apesar de ser vendido a todos nós, somente é acessível a algumas camadas da sociedade, cuja sensação de independência e liberdade não deixa de ser, no limite, também uma ilusão (SENETT, 2012). Para as pessoas comuns, entendemos que, embora o lugar vivido não seja espetacularizado, nossa relação com ele é. Ocupando-o, não estamos normalmente preocupados em construir ali um lugar sui generis (que ele já é), mas em abandoná-lo o quanto antes e, se tudo der certo, subir na sociedade e passar a possuir um espaço espetacular.

Usamos os termos espetacular e ilusório de forma correlata, complementando a análise dos conceitos de espaço e corpografia com o ensaio de Senett (2012) sobre os valores da nossa sociedade. Apesar de o autor comentar especificamente sobre a sociedade estadounidense, acredito que haja um forte paralelo com outras sociedades que se inserem em relações globalizadas. Trata-se de um estudo sobre a mudança de valores morais acompanhada da mudança das relações de trabalho que se deu ao longo do século XX, apontando como a lógica de produção dos mercados globalizados afeta significativamente as relações pessoais. Assim, 
Revista do Programa de Pós-Graduação em Artes da Cena, Universidade Estadual de Campinas

Performing Arts Graduate Program Journal, University of Campinas

embora os lugares não-espetaculares favoreçam o acontecimento das experiências subjetivas reais (e não ilusórias), a probabilidade de essas experiências acontecerem diminui enormemente sob o viés da lógica utilitária que se coloca em função da produção globalizada de bens e serviços e da reprodução constante de ideias que sustentam a ilusão de espetáculo.

Quem somos nós, porém, para julgar o que são relações reais ou ilusórias? Não poderíamos jamais impor qualquer ação que pudesse ser vista como uma atitude arrogante como se ela fosse menos ilusória e mais real do que aquilo que já está instaurado. Contudo, quisemos propor uma pequena subversão a partir de uma breve errância nessa lógica funcional aos mercados - que aqui definimos como aquela que planifica aspectos de nossa vida em transações supostamente neutras de oferta e demanda. Essa lógica é disfuncional às nossas sensibilidades, que são compostas por histórias imparciais, memórias diversas e grande potencial criativo. As relações conflituosas existentes nos locais não-espetaculares são orientadas por uma lógica espetacular de mercado, que por sua vez, como vimos, não encontra sentido na vida real despojada da ilusão de autonomia. Contudo, essa lógica é passível de ressignificação. Como nos chama à atenção Michel de Certeau (2002), o cotidiano pode ser (re)inventado, na medida em que somos capazes de transformar, de maneira única e ao nosso critério, aquilo que nos chega de forma planificada, padronizada e massificada. E assim traímos, felizmente, a ausência de sentido de certas lógicas apenas aparentemente funcionais, e revelamos, para quem quiser ver, sua desfuncionalidade em proporcionar narrativas de vida significativas.

Como nosso trabalho de conclusão de curso poderia contribuir para essa reinvenção? Como vimos, a ressignificação dos componentes mais banais de nossas experiências de vida cotidianas os torna únicos e especiais, propiciando experiências verdadeiramente subjetivas (o que não quer dizer que poderiam assim alcançar a ilusória autonomia plena). Podemos dizer que essas são experiências estéticas, já que, conforme Kastrup (2010, p. 40), “a experiência estética é encontrada na vida, sempre que ela deixa de ser uma banalidade”. Ainda segundo a autora, a "arte produz de modo especial experiências estéticas" (KASTRUP, 2010, p. 40) - o que nos fez acreditar que nosso TCC poderia ser um pequeno estímulo à reinvenção de muitos cotidianos, inclusive os nossos. 
Revista do Programa de Pós-Graduação em Artes da Cena, Universidade Estadual de Campinas

Performing Arts Graduate Program Journal, University of Campinas

Todo o nosso processo criativo foi construído em cima de procedimentos de escuta e de sensibilidade ao nosso entorno. Afinamos nossas percepções e era isso que poderíamos propor a quem quer que nos assistisse. Desenvolvendo o entendimento a respeito do que é "estético" e "artístico", e encontrando em "experiência estética" um conceito que exprime o diálogo entre arte e estética, a análise de Kastrup (2010) pode se aplicar a obras artísticas diversas. Mas, ao trazer a importância da percepção para a experiência estética, a autora parece resumir nossa discussão, apresentando o ponto de vista de Bergson (2006 apud KASTRUP, 2010, p. 40), que "distingue a percepção a serviço da vida prática, movida pelo interesse e colocada a serviço da ação, e a percepção estética, desinteressada e livre das limitações da vida utilitária".

Daí porque, sem desqualificar a vivência urbana cotidiana, mas lembrando que existem possibilidades de experimentá-la que não estejam tão fortemente marcadas pelo utilitarismo, podemos afirmar que na arte a "transformação da percepção é o que realmente importa" (RIBEIRO, 2017, p. 47). Nas performances que acontecem nos espaços urbanos nãoespetaculares, torna-se evidente o diálogo "entre o que existe e o que poderia possivelmente existir, o real e o imaginário, o autêntico e [aquilo] que está na nossa memória"3. Assim, vemos potencializada uma percepção transformada, já que, nesses espaços, o cotidiano é de alguma maneira diretamente transformado pela ação performativa, bem aos olhos do expectador. Este, inserido na própria performance, a seu modo e simplesmente por estar ali, compondo a cena e sendo observado por outras pessoas, torna-se ao mesmo tempo expectador, performer e potencial transformador.

$\mathrm{Na}$ nossa escolha por espaços públicos, não queríamos nem poderíamos usar esses espaços somente como um elemento cênico a mais. Como vimos no conceito de "corpografia", o espaço precisaria estar inscrito em nossos corpos, ao invés de servir como um pano de fundo. Um ponto de vista mais exato sobre os espaços escolhidos é o de que eles seriam a proposta artística em si e nós, o grupo 5+1, um elemento cênico a mais. Contudo, não devemos banalizar nossa atuação, pois

\footnotetext{
${ }^{3}$ Trecho de comunicação oral, cuja transcrição foi cedida à autora, apresentada pela Prof. Dra. Holly Cavrell no VI Seminário Interno de Pesquisas Mario Santana do PPG Artes da Cena - IA - Unicamp, 2018, Campinas.
} 
Revista do Programa de Pós-Graduação em Artes da Cena, Universidade Estadual de Campinas

Performing Arts Graduate Program Journal, University of Campinas

\begin{abstract}
[u]ma ação performática nas ruas não é algo que se deve pensar como sobreposição ao espaço público, ou seja, a performance não se "cola" sobre uma dinâmica já instaurada da cidade como se fosse algo à parte dela. Ela é, necessariamente, uma interferência e, portanto, perturbação daquilo que se poderia supor como "dinâmica normal" (RIBEIRO, 2017, p. 42).
\end{abstract}

Estávamos de fato propondo uma quebra da tradição ao buscar lugares urbanos e nãoconvencionais à dança, por tudo que eles contam e nos permitem dizer. Por mais que não desejássemos provocar aversão por parte das pessoas, transtornando o fluxo normal daqueles lugares, precisávamos fazer com que o convite à desobediência - à modificação e à transformação - fosse irrecusável. Ainda, conforme Fausto Ribeiro (2017, p. 61), que pesquisou a performance nas ruas urbanas, existe nessas ações um desejo de "subversão do cotidiano das cidades". O artista não vai às ruas mostrar seu modo correto de ver as coisas, mas, ao acatar a diversidade ali latente, tem o propósito proporcionar a irrupção de uma multiplicidade de subversões. Assim, em acordo com o que vimos discutindo,

\footnotetext{
[a] desobediência, então, liga-se à busca de outras formas de relação com a cidade, negando ou, no mínimo, criticando as formas-padrão do jogo funcional do mercado de consumo, do mundo do trabalho e dos projetos governamentais, que, em geral, vêm reforçar os anteriores. (RIBEIRO, 2017, p. 61)
}

\title{
A passos lentos
}

De início, fomos tímidas. Como lembra Ribeiro (2017), parte do propósito e do caráter inovador das performances em espaços públicos reside no fato de não ser necessário convidar nem atrair uma plateia, além das pessoas que já ocupam o lugar. Nesse caso, o autor fala especificamente do teatro de invasão, termo cunhado por Carreira (2007 apud RIBEIRO, 2017), para designar a performance teatral que toma o espaço de assalto, de surpresa. Em nossas primeiras experimentações, contudo, acredito que nós é que fomos tomadas de assalto pelo espaço. Assim, nossa primeira aventura, num lugar pouco movimentado do próprio campus universitário, teve poucos expectadores. A Figura 2 é a cena final de uma performance curta montada no contexto do encerramento das aulas com Gustavo Ciríaco, artista residente no 
Revista do Programa de Pós-Graduação em Artes da Cena, Universidade Estadual de Campinas

Performing Arts Graduate Program Journal, University of Campinas

Departamento de Artes Corporais da Unicamp no primeiro semestre de 2017. O artista brasileiro, radicado em Portugal, nos convidou a colocar em prática um pouco de sua pesquisa sobre performances site specific. Embora nosso estudo para o TCC não se pretendesse site specific, essa foi uma oportunidade de sair das salas de aula e observar com mais cuidado as exigências de outros espaços. Nas performances em espaços não-convencionais, nem sempre temos o tempo de que gostaríamos para perceber como o espaço configura a criação artística.

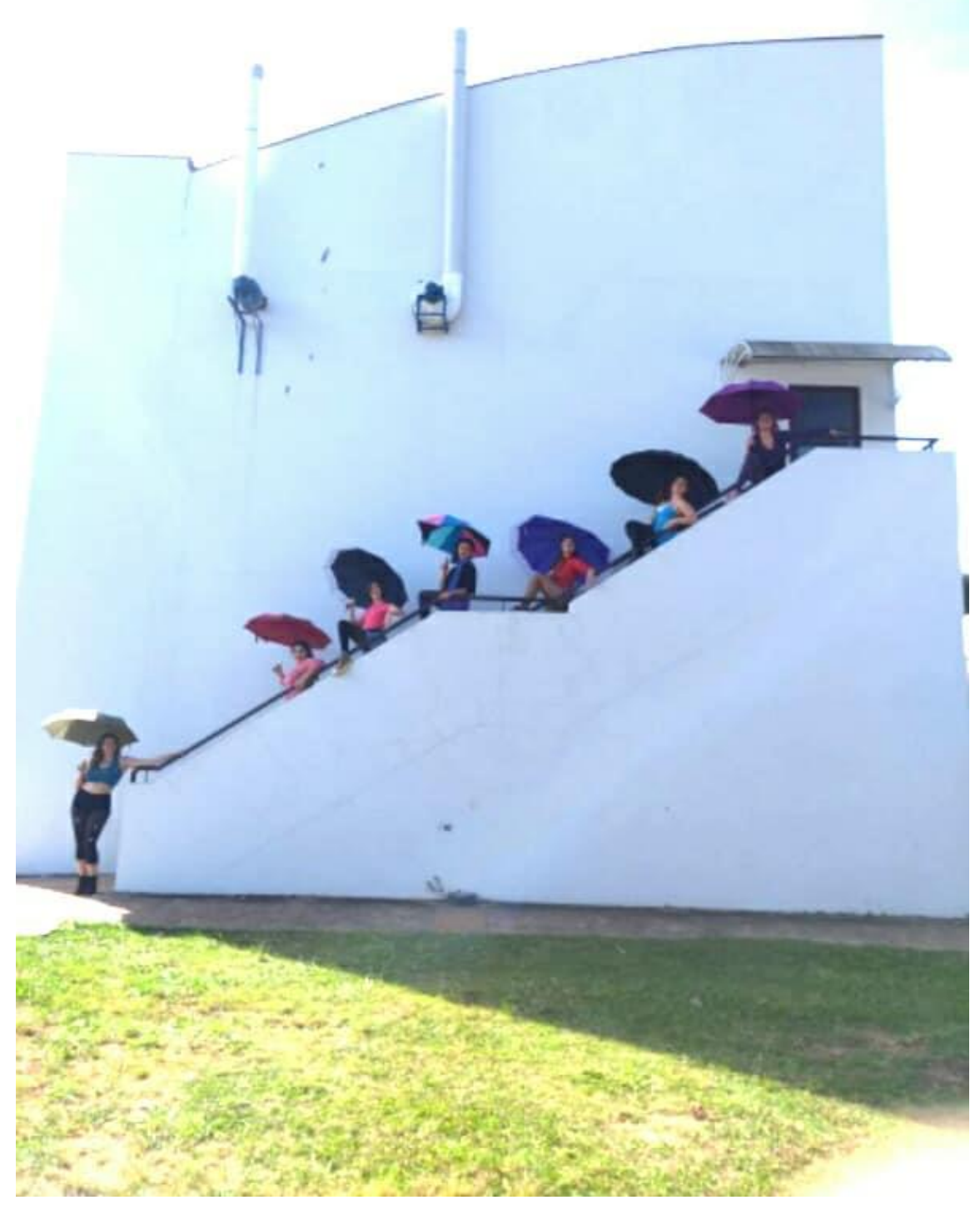

Figura 2- Cena de estudo site specific. Legenda: Unicamp, Campinas, 2017. Foto de autoria desconhecida. 
Revista do Programa de Pós-Graduação em Artes da Cena, Universidade Estadual de Campinas

Performing Arts Graduate Program Journal, University of Campinas

Logo nos arriscaríamos em locais fora da Unicamp: o parque do Taquaral e a rodoviária de Campinas. Dando continuidade ao treinamento de percepção do espaço, sentimo-nos à vontade para realizar pequenas performances improvisadas. Aos poucos, começaríamos a traduzir nossos conhecimentos de dança e de espaços públicos - nossas corpografias - em uma performance. Nossas primeiras tentativas denotaram a falta de fluência na tradução daqueles conhecimentos. Montamos uma cena inteira numa sala de ensaio e a levamos para um espaço de grande circulação: as paredes explodiram infinitamente e tivemos dificuldade em nos fazer presentes na amplitude do novo espaço. Por outro lado, tentamos reproduzir cenas da rodoviária numa praça no campus. Demoramos ao perceber que a cena - naturalmente inusitada na rodoviária - parecia despropositada na praça.

Sentimo-nos traídas. Ao contrário do que esperávamos, não havia palavras que substituíssem umas às outras completamente. Percebemos que as melhores traduções não levam as palavras ao pé da letra. São versões. Porém, por não retratarem fielmente seu par original, as versões não deixam de ser, essencialmente, traições. As versões de sensações irreprodutíveis podem, no máximo, aproximar sentidos. Teremos assim sensações daquilo que existe e daquilo que poderia possivelmente existir. Parece-me que, para aproximar esses sentidos, conectando o que existe e o que poderia existir, é preciso ser íntima dessas sensações, minimamente reconhecendo-as. Uma tal tradução entre o que existe e o que pode existir é uma como uma colagem desses dois textos, uma versão de tradução simultânea; é o processo transformador que

\footnotetext{
"ocorre primeiramente através do entendimento dos processos naturais que ocorrem em um espaço, e não pela imposição de uma visão artística. Só então o artista interfere com o comum e a homogeneização que nos rodeia e procura maneiras de atrair seus observadores e ajudá-los a olhar as paisagens de forma diferente". ${ }^{4}$
}

Portanto, na medida em que desejávamos retratar e instigar encontros, éramos também instadas a produzi-los incessantemente na forma de conexões hipotéticas entre mundos existentes e mundos possíveis. Aos poucos, fomos tecendo uma teia de sentidos que nos

\footnotetext{
${ }^{4}$ Trecho de comunicação oral, cuja transcrição foi cedida à autora, apresentada pela Prof. Dra. Holly Cavrell no VI Seminário Interno de Pesquisas Mario Santana do PPG Artes da Cena - IA - Unicamp, 2018, Campinas.
} 
Revista do Programa de Pós-Graduação em Artes da Cena,

Universidade Estadual de Campinas

Performing Arts Graduate Program Journal, University of

Campinas

conectavam e produziam também o fio condutor às pessoas que ocupavam os espaços da nossa dança. Chamamos nosso trabalho de "TEIA": além de contar com uma teia de elásticos montada entre as árvores da praça do Marco Zero da Unicamp, nossa peça funcionava também como uma teia de aranha que se instala no caminho de insetos desavisados (Figura 3). Quem passasse pela praça poderia ser capturado pela estranheza das nossas ações, sem previsão de volta ao curso normal das coisas.

Uma performance em espaços públicos não teria razão de ser sem os encontros vividos entre performers e expectadores. Assim, traíamo-nos - ou talvez déssemos o golpe final numa traição cotidiana. Nossa versão simultânea do que existe e do que poderia existir se completou num estado de presença que não se fechava na individualidade de cada uma das intérpretes. Não estávamos vivendo cada uma um instante só seu, mas nos conectávamos com o entorno, permitindo infinitas significações por parte de quem observasse - e, portanto, se tornasse criador conosco. Esse estado de presença é requisito básico para que se estabeleça uma empatia imediata entre performer e expectador, fazendo surgir entre eles uma intimidade, cujos ares de cumplicidade e capacidade de criação de sentido lhes confundem os papéis. Somos finalmente traídos em nossos caminhos automáticos e cotidianos; somos traídos em nossos papéis sociais; ainda que pela brevidade de um instante, somos traídos, felizmente, pela arte.

\section{Considerações finais}

Minha ficha-corpo se transformou. Eu trago hoje uma corpografia com novas inscrições urbanas. É preciso considerar primeiramente o ganho em termos de repertório de movimentos. A percepção do espaço inabitual trouxe novas possibilidades de movimentação ao corpo. Desde então, busco cada vez mais integração ao espaço e tenho me utilizado de ferramentas específicas para continuar essa pesquisa. $\mathrm{O}$ caminhar na cidade tornou-se um experimento constante $^{6}$. O parkour também surgiu como uma prática que propõe desafios de locomoção,

\footnotetext{
5 “TEIA" foi orientado pela professora Holly Cavrell e codirigido por Raíssa Costa e Nicolli Tortorelli. Performamos eu, Janaína Betel, Letícia Benevides, Maria Beatriz Cantore Ferro e Nina Raw.

${ }^{6}$ Como vimos no começo do texto, os gestos cotidianos interessam aos artistas da cena há algum tempo. Nesse sentido, a pesquisa em dança conta, atualmente, com diversos estudos sobre o movimento comum dançado no
} 
Revista do Programa de Pós-Graduação em Artes da Cena, Universidade Estadual de Campinas

Performing Arts Graduate Program Journal, University of Campinas

cuja superação depende enormemente da concentração e da conexão com o espaço. Enquanto processo e produto artístico, sobretudo, a experiência de dançar em espaços não-convencionais demandou um aprofundamento e uma ampliação da percepção do entorno que dificilmente poderia ser trabalhada em sala de aula. De volta a esse ambiente, percebi que a atenção à cena, em oposição a certo ensimesmamento, teve grande ganho. Ou seja, houve um avanço no sentido de fortalecer a presença cênica, que é essencial ao trabalho do artista da cena, qualquer que seja o espaço escolhido para se apresentar.

Entre os aprendizados de dançar fora dos espaços convencionais estão os desafios de lidar com: os imprevistos da rua, as limitações ao movimento dadas pelo espaço irregular, e a necessidade de gerar empatia ampliada pela ausência de barreiras entre artista e público. $\mathrm{Na}$ raiz desses desafios estão os questionamentos trazidos neste artigo, que foram motivados e expressos pela dança nos espaços não-convencionais, mas dizem respeito a problemáticas mais amplas de nossa sociedade. Trata-se de questões sobre os espaços que construímos e ocupamos, as formas como a cidade conforma nossos corpos, e as relações que instauramos com as pessoas que participam coletivamente da construção cotidiana de nossos caminhos. A poética dançada nos lugares de pesquisa proporcionou um olhar subversivo sobre essas questões, apontando caminhos errantes, desviantes do padrão instalado.

cenário urbano, a exemplo de AnDanças, trabalho da artista e pesquisadora, Laís Rosa, comentado por Villen (2018). 
Revista do Programa de Pós-Graduação em Artes da Cena, Universidade Estadual de Campinas

Performing Arts Graduate Program Journal, University of Campinas

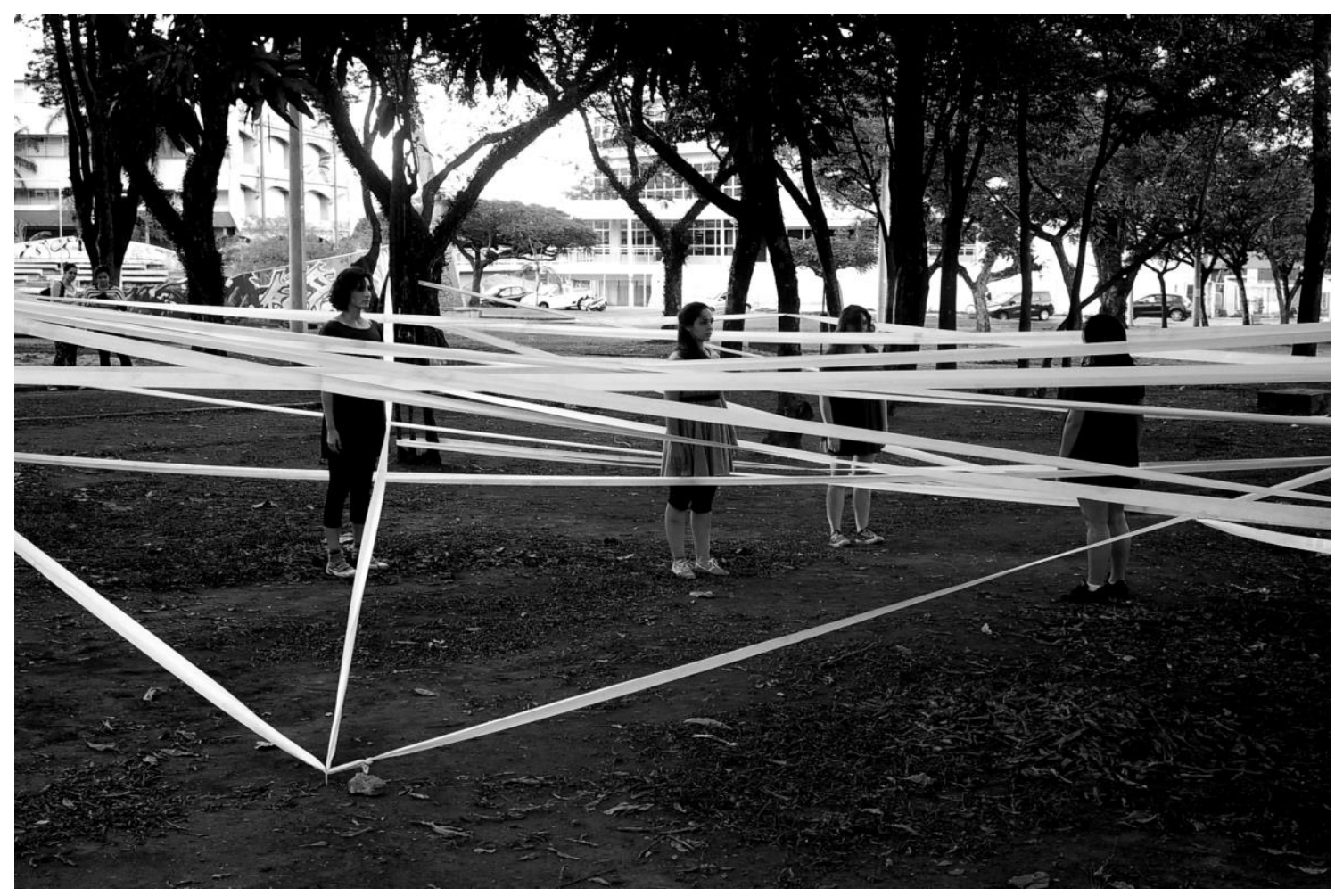

Figura 3 - TEIA. Unicamp, Campinas, 2017. Fonte: fotógrafo Rodrigo Cruz.

Vimos nos encontros uma maneira de vivenciar novas relações conosco mesmas, com outras pessoas e com o espaço, descobrindo nelas seu potencial transformador. A cada ensaio (todos, inevitavelmente, uma pré-estreia do nosso trabalho) e a cada apresentação, construímos uma teia de relações instantâneas, captadas pelo diálogo com o que temos de permanente e comum: os caminhos rotineiros, as buscas de todo dia, a transmissão, a recepção e a criação conjunta da empatia. Performers e expectadores, que já não se rotulavam dessa maneira, mas simplesmente conviviam no espaço, tornaram-se atentos às interações surgidas, imaginadas e criadas em suas vidas.

\section{Referências}


Revista do Programa de Pós-Graduação em Artes da Cena, Universidade Estadual de Campinas

Performing Arts Graduate Program Journal, University of Campinas

CARREIRA, A. A cidade como dramaturgia do teatro de invasão. In: XI Encontro Regional ABRALIC, 2007, São Paulo. Anais do XI Encontro Regional da ABRALIC, São Paulo: Universidade de São Paulo, 2007.

CAVRELL, H. E. A Intimidade de Apresentações em Espaços Públicos. In: IX Congresso da Associação Brasileira de Pesquisa e Pós-Graduação em Artes Cênicas, 2017, Uberlândia. Memória Abrace XVI - Anais IX Congresso da Associação Brasileira de Pesquisa e PósGraduação em Artes Cênicas. Uberlândia: ABRACE, 2016.

CERTEAU, Michel. L’invention du quotidien. Arts de faire. Paris: Gallimard. 2002.

CIE WILLI DORNER. Bodies in urban spaces. In: Première: Festival Paris Quartier d'été, July 2007. 2, Paris: 2007. Disponível em: <http://www.ciewdorner.at/index.php?page=work\&wid=26>. Acesso em: 20 mai. 2018.

CONCEIÇÃO|CONCEPTION. Babel: Tradições, Traduções e Traições. Campinas, SP, v. 7, n. 2, jul./dez. 2018.2 Disponível em: <https://periodicos.sbu.unicamp.br/ojs/index.php/conce/issue/view/1549>. Acesso em: 29 jul. 2019.

KASTRUP, Virginia. Experiência Estética Para uma Aprendizagem Inventiva: notas sobre a acessibilidade de pessoas cegas a museus. Informática na Educação: teoria \& prática, Porto Alegre: v. 13, n. 2, p. 38-45, jul./dez. 2010.

JACQUES, P. Corpografias urbanas. In: IV ENECULT - Encontro de Estudos Multidisciplinares em Cultura, 2008, Salvador-BA. IV ENECULT - Encontro de Estudos Multidisciplinares em Cultura: Anais. Salvador: UFBA, 2008. ISBN 978-85-60667-21-5

LEPECKI, André. Planos de composição. In: GREINER, C; SANTO, C.E.; SOBRAL, S. (Org.) Cartografia Rumos Itaú Cultural Dança 2009-2010. São Paulo: Itaú Cultural, 2010.

RIBEIRO, Fausto. Corpos desobedientes em diálogo com a rua: processos de construção de ações performáticas no ambiente da cidade. Dissertação (Mestrado em Artes da Cena) Instituto de Artes, Universidade Estadual de Campinas, Campinas, 2017.

SENETT, Richard. A corrosão do caráter. 17ª edição. São Paulo: Editora Record, 2012. ISBN 85-01-05461-5 
Revista do Programa de Pós-Graduação em Artes da Cena,

Universidade Estadual de Campinas

Performing Arts Graduate Program Journal, University of Campinas

VILLEN, G. Pesquisa investiga o caminhar na cidade. Unicamp - Notícias. Campinas, 01 out. 2018. Disponível em: <http://www.unicamp.br/unicamp/noticias/2018/10/01/pesquisainvestiga-o-caminhar-na-cidade>. Acesso em: 16 out. 2018. 